\title{
Langdon Winner's Intellectual Trajectory and Political Engagement: A Latin-American Perspective from Ecuador
}

\author{
MARÍA BELÉN ALBORNOZ \\ FLACSO I FAIRWORK \\ ECUADOR
}

\begin{abstract}
In the 2020 Prague Virtual Conference of the Society for Social Studies of Science (4S), Langdon Winner was awarded the society's John D. Bernal Prize jointly with Sharon Traweek. The Bernal Prize is awarded annually to individuals who have made distinguished contributions to the field of STS. Prize recipients include founders of the field of STS, along with outstanding scholars who have devoted their careers to the understanding of the social dimensions of science and technology. This response to Winner's Bernal lecture considers his legacy beyond the US. The author traces Winner's influence in Ecuador and Latin America more generally through a tracing back of Winner's politea which draws on Plato's technē as a model for understanding inherently political artifacts.
\end{abstract}

\section{Keywords}

Langdon Winner; artifact; education; innovation; technē; politeia

\section{Introduction}

Langdon Winner was born and raised in San Luis Obispo, California. When he arrived at the University of California Berkeley in early 1960s, he witnessed first-hand how the student movement, the Black Panther Party, artists, and other counterculture movements fought for civil rights and structural change in society. In his own words, Berkeley "became a place in which politics in the plaza and learning in the classroom were never far removed" (Winner 1977). Deeply impacted by this decade's events, the aftermath of Vietnam, racism, militarism, the growing role of technology in society, and worldwide movements for decolonization, Winner has maintained a nonstop dedication to exploring, studying and contributing to a better understanding of the challenges and fractures of today's society. He is not only an exceptional scholar-he is an intellectual who has the capacity to enrich public life (Jacoby 1987).

His essay "Do Artifacts Have Politics?" published in 1980 put him in the spotlight of academic debate. His claim that artifacts have political properties that can embody forms of authority and subordination, and, that they are, therefore, able to discriminate, pose threats and maintain regimes of power, was rapidly welcomed. In that essay, Winner emphasized the need for a theory of technological politics that can "draw attention to the momentum of large-scale sociotechnical systems, to the response of modern societies to certain technological imperatives, and to the all too common signs of the adaptation of human ends to 
technical means" (Winner 1980,123). For more than four decades Winner has contributed to political theory and philosophy fields researching the role of science and technology in the shaping of democracy. His work on technological politics has become one of the most important references in Science and Technology Studies (STS).

Winner's observation about "technologies as form of life" that reconstitute the conditions of human existence (Winner 1986; 1983) is based on the concept of "forms of life" that Ludwig Wittgenstein elaborated in Philosophical Investigations. According to Winner, technical culture has focused on the making and use of technology by excluding the analysis of its own foundations. Ordinary speech tends to reinforce the idea that the tool-like features of technology encourage us to disregard how technologies "provide structure for human activity" $(1983,251)$. But language not only deals with naming, it is also "part of an activity, or of a form of life" (Wittgenstein 1958, 11). When technologies are designed and put to use there is nothing secondary about their formative presence because they are immediately involved in shaping important patterns of human institutions and activities. Thus, there is a "second nature" that emerges from the use of artifacts, systems and techniques because the construction of a technical system involves the reconstruction of relationships and social roles (Winner 1983, 254).

The political forms of life to which he dedicates special consideration are the ones related to the theory of politics where citizenship and participation are at the core of the political imagination and involve order, authority, power, freedom and other fundamental themes of Western political thought. Making choices about technological innovation and technological design illuminates the political ideas embedded in artifacts and technological systems, as well as their distinctive contribution to the creation of forms of political life in a society. Society must confront sociotechnical development in order to control its own structural evolution because the introduction of new technologies is inextricably linked to the process of social reconstruction. Otherwise, artifacts can be regarded as morally neutral, which leads to a "technological somnambulism" $(\underline{1986,10)}$ or as a source of anxieties where technology is self-governed, independent and associated with a process of change in which society is progressively altered by an expanding scientific technology. Technologies produce frameworks of order for the modern world. Hence it is worth trying to understand the forms of authority, justice, public good, and freedom that their order entails $(\underline{1983,262})$.

Strongly influenced by Ludwig Wittgenstein, Karl Marx, Jacques Ellul, Herbert Marcuse, Martin Heidegger, Lewis Mumford, and Hanna Arendt among others, Winner's work on autonomous technology has become a methodological touchstone in order to explain a range of related issues, such as technocracy, determinism, technical imperatives and "technological politics" (Winner 1977, 237). Following Ellul's thought that technique has become autonomous and obeys its own laws and that, therefore, "there can be no human autonomy in the face of technical autonomy" (Ellul 1954, 138); Winner explores the profound influence of the technosphere in today's society. His primary concern is how technology is affecting modern politics at a time when political theory seldom explores technology as a central issue. As conventional notions of progress are replaced by more fashionable concepts of innovation, efficiency, and productivity, the autonomy of technology seems to reconstruct people's lives and their institutional arrangements. A more 
democratic understanding of technology is needed to open up new possibilities of citizenship in the public sphere, which can be achieved by involving citizens in the design and configuration of technological systems.

The origins of STS have two different contexts, one intellectual and the other socio-political. Winner's work has impacted both by theorizing the effects of scientific technology upon society. Committed to the public deliberation of technological design, he has argued that the "technology assessment" movement has become a clear example of how institutions can promote a democratic shaping of technology by actively analyzing and recommending technological pathways compatible with the common good. When encapsulated in policy units, technology assessment institutions have been able to modestly improve communication between scientists, the media, and decision-makers, and to make issues about sciencebased technologies more accessible to policy-makers and to the wider public as well. Winner argues that contrary to what has happened in Europe, in American society this movement has lost its grip due to a weaker civic engagement (2020) and the replacement of the common good by some more "fashionable 21st century notions such 'entrepreneurship,' 'shareholder value' and (best of all!) 'innovation'” (Winner 2018).

In this regard, the field of STS has also changed. According to Winner, the intellectual and incipient political movement of a half century ago, which shared the idea that elected leaders, social organizations, academia, and professional organizations could debate about the complexities of emerging technologies and advice on the opportunities and the possible dangers that ought to be mitigated, has moved into the role of networks, social constructions, gender, culture, and assemblages in shaping certain characteristics of technology and its consequences. Far from the technology assessment movement and the self-conscious, broadly based democratic project of deliberation, debate and choice, the cult of innovation is becoming a new paradigm that erases a teaching project committed to the common good.

A theory of technological politics is needed in order to discuss the place of technology in human life. Because technology is deeply embedded in today's market-centered social order, the sociotechnical configurations that regulate people's lives can be changed only if people demand the right to influence the design of technologies that condition their lives. If Plato's technē serves as a model for politics, in Winner's terms, technē itself has become politeia, a very powerful mode of institutionalization where technological systems are highly compatible with centralized and hierarchical managerial control. Such inherently political technologies have tended to eclipse other forms of political and moral reasoning by separating technological systems from the polity as a whole. Winner questions whether the internal politics of technology and the politics of the whole community can be so easily separated, because of the rational arrangements and the hierarchical structures of authority that sociotechnical systems present to us have such a powerful shaping role $(\underline{1986,36-48)}$.

As a dedicated teacher and active citizen, Winner has exposed ways in which technē works as a powerful politeia, and how it has supported an era of mythinformation and cyberlitertarianism. His work embraces a wider public within projects of critical thinking. While he masters a prose dedicated to encouraging a new intellectual generation to propel cultural life, Winner's sharp thinking has also influenced policy-makers in different geographies, epistemic communities and citizens. His books, articles, presentations, blog entries, 
magazine columns, and videos are parts of a conscious intellectual project which cherishes direct and lucid writing as a way to awaken society.

His work has had a transnational impact strongly influencing scholars from diverse STS communities. From Argentina to Mexico STS teaching programs have included his texts in their curricula and researchers have used them in their analytic frameworks, which has contributed to making his work known to students and young researchers. In appreciation of his contribution to Latin American STS, the Association for the Social Studies of Science and Technology invited him to be the keynote speaker who opened the ESOCITE congress in Brazil in 2016. His relationship with the STS community in Ecuador has been even more significant. Winner has become a key figure in FLACSO's STS program through his seminars, workshops and conferences, inspiring students and researchers for more than 10 years.

He has been invited by the Ecuadorian government and has contributed to alerting decision-makers to the risk of mythinformation as an ideology where it is assumed that citizens need information, that information becomes knowledge, that knowledge is power, and that increased access to information enhances democracy and equalizes social power (Winner 1986). Therefore, Winner's intellectual trajectory must be understood in relation to the social realities and the political culture he has attempted to unveil. Following how ideas may foster or hinder social process, encourage or inhibit change, his public work has made visible a worldview that is taking form by a systematic integration of collective beliefs and objectives characterized by technological determinism and power fantasies at the end of modernity (2014a). Confronting these fantasies with activists, indigenous peoples, academics, policy-makers, hacktivists, and visionaries has been an essential part of his efforts to boost open knowledge and the new commons approach into public affairs, education and social innovation (2014b).

Antonio Gramsci's message that intellectuals must not only think, but also act has been key to Winner's engagement with public life and has inspired me to take action through government work. First as founder of CTS Lab, a laboratory for the co-creation of public policies, and afterward as advisor to the Minister of Education and as a member of the National Education Council of Ecuador in 2018.

Most of all, his intellectual work has evolved hand in hand with his active participation in civic life. Rooted in the principles that guided the origin of STS, Winner has dedicated his life to studying the imbrications of a technological era that affects the ability of citizens to make decisions about the technological systems that govern their lives. His contributions to the politics of technology have explored a wide range of issues such as technology and education; militarism; environmental issues; the homogenization of cultural expression; and technological surveillance.

Winner calls for public responsibility to disentangle "The Cult of Innovation," for more critical thinking, for new times for technological assessment. His legacy is not only academic, but calls for action and 
participation in the public sphere. In sum, he insists that "every person on Earth has the right to a role in shaping the technical instruments, processes and institutions that affect their well-being" (Winner 2017).

\section{Author Biography}

María Belén Albornoz is a Professor and Researcher at the Latin American Faculty of Social Sciences (FLACSO-Ecuador). She is the Principal Investigator of the Fairwork Project in Ecuador, Coordinator of the PhD Program on Public Policy, and Coordinator of the Science, Technology and Society Laboratory (CTSLAB). She serves as President of the Ecuadorian Society for Social Studies, as Council Member of the Society for Social Studies of Science (4S), and as Board Member of the Society for the Studies of New and Emerging Technologies (S.NET).

\section{References}

Ellul, Jacques. [1954] 1964. The Technological Society. New York: Vintage Books.

Jacoby, Russell. 1987. The Last Intellectuals. American Culture in the Age of Academe. New York: Basic Books.

Winner, Langdon. 1977. Autonomous Technology. Technics-out-of-Control as a Theme in Political Thought. Cambridge, MA \& London: The MIT Press.

—.1980. "Do Artifacts Have Politics?" Daedalus 109(1): 121-36.

—. 1983. "Technologies as Forms of Life." In Epistemology, Methodology and the Social Sciences Boston. Studies in the Philosophy of Science, Volume 71, edited by Robert S. Cohen and Marx W Wartofsky. 249-64.

—.1986. The Whale and the Reactor. A Search for Limits in an Age of High Technology. Chicago and London:

The University of Chicago Press.

—. 2014a. "Power Fantasies at the End of Modernity." Technopolis.

https://www.langdonwinner.com/technopolis/2014/12/power-fantasies-at-end-ofmodernity.html.

—.2014b. "The Buen Conocer Summit of the FLOK Society in Quito." Technopolis.

https://www.langdonwinner.com/technopolis/2014/06/session-of-free-libre-openknowledge.html.

—. 2017. "Is There A Right To Shape Technology?" Technopolis.

https://www.langdonwinner.com/technopolis/2017/8/27/is-there-a-right-to-shapetechnology.

—.2018. "A Letter to My Friends in Norway," Technopolis.

https://www.langdonwinner.com/technopolis/2018/1/20/a-letter-to-my-friends-innorway? rq=common\%2ogood.

—.2020. "The Democratic Shaping of Technology: Its Rise, Fall and Possible Rebirth." Technopolis. https://www.langdonwinner.com/other-writings.

Wittgenstein, Ludwig. 1958. Philosophical Investigations. London: Basil Blackwell Ltd. 